\title{
Anger in social conflict: Cross-situational comparisons and suggestions for the future
}

\author{
Gerben A. Van Kleef - Eric van Dijk - Wolfgang \\ Steinel · Fieke Harinck · Ilja van Beest
}

Published online: 1 June 2007

(C) Springer Science + Business Media B.V. 2007

\begin{abstract}
This paper reviews research on the role of anger in conflict. We distinguish between intrapersonal and interpersonal effects of anger, the former referring to the impact of parties' feelings of anger on their own behavior and the latter referring to the impact of one parties' anger on the other's behavior. We further compare the effects of anger across a variety of conflict settings, including negotiation, ultimatum bargaining, prisoner's dilemma, resource dilemma, and coalition formation. At the intrapersonal level, anger is associated with competition in all conflict settings. In contrast, the interpersonal effects of anger differ across situations, with anger sometimes eliciting cooperation, sometimes eliciting competition, and sometimes having no effect. Based on the research reviewed, we conclude that the interpersonal effects of anger in conflict are determined by the level of interdependence of the parties, their information processing tendencies, and the justifiability of the anger expressions.
\end{abstract}

Keywords Anger · Conflict · Negotiation · Ultimatum bargaining · Prisoner's dilemma $\cdot$ Resource dilemma $\cdot$ Coalition formation

\section{Introduction}

Conflict is a natural fact of life. Whether we focus on interactions between individuals, groups, organizations, or nations - conflicts are omnipresent. Often, the divergent

Preparation of this paper was facilitated by a Veni grant from the Netherlands Organization for Scientific Research (NWO 451-05-010) awarded to Gerben A. Van Kleef.

G. A. Van Kleef

Department of Social Psychology, University of Amsterdam, Roetersstraat 15, 1018 WB

Amsterdam, The Netherlands

e-mail: g.a.vankleef@uva.nl

E. van Dijk · W. Steinel · F. Harinck · I. van Beest

Leiden University, Leiden, The Netherlands 
interests that lie at the heart of conflict give rise to intense emotions, which may in turn strongly influence conflict development (Barry et al. 2004). Of the range of emotions that may arise in conflict, anger is perhaps the most prominent and pervasive (Allred 1999). Anger is closely related to fairness judgments (Averill 1982), which play an important role in deal making and dispute resolution (Daly 1991). For a thorough understanding of the dynamics of conflict resolution and escalation it is therefore crucial to know how parties in conflict are influenced by their own and others' anger. The purpose of this article is to review research that speaks to the role of anger in social conflict.

Social conflict is a broad term that encompasses different types of conflict situations, which may call for different modes of conflict resolution. In general, social conflict may be said to occur when two or more parties have (or perceive) a divergence of interests (Pruitt and Carnevale 1993). This divergence of interests may take on many guises, ranging from disagreement about the price of a second-hand car to marital disagreements to political disagreements, to name but a few. Conflicts may vary tremendously in terms of the stakes, the likelihood and possible consequences of stalemate, and the relationship between the parties. Given these differences, the question arises whether anger may have differential effects depending on the type of conflict situation or conflict resolution procedure. An explicit goal of this paper is therefore to compare the effects of anger across different conflict settings.

\section{Anger in social conflict}

In conceptualizing the role of anger in social conflict, it is useful to make a distinction between intrapersonal effects and interpersonal effects (Morris and Keltner, 2000; Van Kleef et al. 2004a). Intrapersonal effects refer to the influence of an individual's affective state on his or her own cognitions, strategies, perceptions, and behaviors. Interpersonal effects, on the other hand, refer to the influence of one individual's affective state on one or more other individuals in the social context. Below we first provide a brief summary of research on the intrapersonal effects of anger in various types of social conflict, namely negotiation, ultimatum bargaining, and two types of social dilemmas (prisoner's dilemma and resource dilemma). We then turn to a more elaborate discussion of recent work on the interpersonal effects of anger in negotiation, ultimatum bargaining, and coalition formation. Subsequently we compare the effects of anger in these different conflict settings. On the basis of this analysis we advance a number of propositions and conclusions concerning the role of anger in conflict. We conclude by suggesting directions for future research.

\subsection{Intrapersonal effects}

Most research on intrapersonal effects has focused on diffuse positive and/or negative affect (e.g., Carnevale and Isen 1986; Baron 1990; Baron et al. 1990; Forgas 1998). This research has been extensively reviewed elsewhere (see Barry et al. 2004). The present discussion will be confined to studies that explicitly examined the intrapersonal effects of anger as compared to one or more other discrete emotional states. We have been able to identify only about a handful of studies that explicitly investigated the intrapersonal effects of discrete anger in social conflict. These studies, which have 
looked at the role of anger in negotiation, ultimatum bargaining, prisoner's dilemma, and resource dilemma situations, are summarized below.

\subsubsection{Negotiation}

Negotiation can be defined as "a discussion between two or more parties with the apparent aim of resolving a divergence of interest and thus escaping social conflict" (Pruitt and Carnevale 1993, p. 2). The first empirical study we are aware of that explicitly addressed the intrapersonal effects of discrete anger in negotiation was conducted by Allred et al. (1997). In a simulated negotiation experiment they manipulated anger and compassion and found that negotiators with high levels of anger and low levels of compassion had less concern for the other's interests and had less desire to work with the other in the future than did negotiators who had more positive emotional regard for the other party. Allred et al. further found that negotiators who felt high anger and low compassion for each other achieved lower joint gains.

Compatible findings were obtained in a recent study on emotions in dyadic negotiation by Butt et al. (2005). They measured both negotiating parties' levels of anger, pride-achievement, gratitude, and guilt-shame. Among other effects they found a positive and significant association between anger and dominating behavior, indicating that negotiators with higher levels of anger adopted a more competitive stance in the course of the negotiation than did those with lower levels of anger.

\subsubsection{Ultimatum bargaining}

Pillutla and Murnighan (1996) were the first to document intrapersonal effects of anger in ultimatum bargaining. The ultimatum bargaining game, developed by Güth et al. (1982), is a very simple and elegant game to study two-person bargaining behavior. In this game, two players have to decide on how to distribute a certain amount of money. One of the players, the allocator, offers a proportion of the money to the other player, the recipient. If the recipient accepts, the money will be distributed in agreement with the allocator's offer. The main focus of prior research on the ultimatum bargaining game has been to investigate whether bargainers are primarily motivated by self-interest or by fairness. In general, allocators often make fair offers by offering half of the money to the recipient, and low offers (e.g., where the allocators only offer $20 \%$ of the money to the recipient) are often rejected by the recipient (see for overviews e.g., Güth and Tietz 1990; Camerer and Thaler 1995; Handgraaf et al. 2003; Thaler 1988; Van Dijk and Tenbrunsel 2005).

Pillutla and Murnighan's (1996) study focused on the role of perceived fairness and emotions in the recipient's decision whether or not to reject low offers. The extent to which recipients could evaluate the fairness of the offer was manipulated by providing either complete or incomplete information about the amount of money that was to be divided. The results of this study showed that participants were more likely to reject an offer if they were able to evaluate its fairness, and, more important for present purposes, that the anger resulting from perceived injustice was a better predictor of rejections than was unfairness per se. Compatible findings were reported by Bosman et al. (unpublished), who showed that the probability of rejection of an ultimatum offer was positively related to the intensity of experienced anger, irritation, contempt, sadness, and envy. 


\subsubsection{Iterated prisoner's dilemma}

Kassinove et al. (2002) examined the influence of trait anger on competitive versus non-competitive decisions in an iterated prisoner's dilemma game. In any single trial of the iterated prisoner's dilemma game, the best payoff for an individual results when s/he chooses a competitive response while the counterpart chooses a non-competitive (or cooperative) response. In the long run, however, when playing multiple trials, the payoffs are greatest for both parties if they both consistently choose the non-competitive option. Kassinove et al. used the iterated prisoner's dilemma to simulate behavior in wartime interactions. In a series of 100 trials participants could attack their opponent (the competitive option) or wait for troop reinforcements (the non-competitive option). Kassinove et al. found that participants with high levels of trait anger made more competitive/attack responses than did participants with low levels of trait anger, especially when they were paired with a high trait anger partner.

\subsubsection{Resource dilemma}

Knapp and Clark (1991) examined the effects of anger and a number of other emotions in a resource dilemma, in which individual interests are at odds with collective interests. In a laboratory simulation, participants harvested fish from a common and depletable resource pool that was only partially replenished at fixed time intervals. In this situation, the dilemma consists in the fact that although it is profitable for individual fishers to maximize their selfish interests by harvesting all they can, if all fishers were to do so the resource would be depleted and everyone would be collectively worse off (for overviews of research on these and other social dilemmas, see Dawes 1980; Messick and Brewer 1983). Before playing this fishing dilemma game, participants were experimentally induced to feel angry, sad, or happy (or neutral in a control condition). Across two experiments, Knapp and Clark found that angry and sad participants were both more competitive (i.e., they took more fish) than were participants in a happy or neutral mood.

\subsubsection{Conclusion}

In sum, a number of studies on the intrapersonal effects of anger in four different conflict settings have revealed that anger tends to elicit competitive behavior. Interestingly, the effects of anger appear to be unaffected by the type of conflict. In negotiation, ultimatum bargaining, iterated prisoner's dilemma, and resource dilemma settings anger was consistently found to be associated with competitive behavior. As we shall see in a moment, the interpersonal effects of anger are more complex, as they appear to be at least in part contingent on various aspects of the conflict situation.

\subsection{Interpersonal Effects}

In his 1996 article titled "Emotions are social," Parkinson proposed that emotions are best viewed as social rather than individual phenomena. Indeed, inspired by the early writings of Darwin (1872), researchers have identified a number of important social functions of emotions (e.g., Frijda 1986; Frijda and Mesquita 1994; Keltner and Haidt 1999; Oatley and Jenkins 1992). At the interpersonal level emotions convey information to others about an individual's feelings (Ekman 1993), social intentions 
(Fridlund 1992; Van Kleef et al. 2004a), and orientation toward the relationship (Knutson 1996). Further, emotions may evoke reciprocal or complementary emotions in others that may in turn help individuals to respond to significant social events (Keltner and Haidt, 1999). And lastly, emotions may serve as incentives or deterrents for other individuals' social behavior (Klinnert et al. 1983). Extrapolating from these general social functions, expressions of anger in conflict may for example serve as a threat ("I will harm you if you do not back down"), communicate a competitive stance ("I will not relent in this competition"), or signal one's commitment to a particular issue ("this issue is too important for me to concede on").

The idea that emotions can influence the flow of actions at the interpersonal level is of course highly relevant to the study of anger in social conflict. In situations where people depend on each other for their outcomes, the question of how expressions of anger influence conflict development is of the utmost importance for a complete and thorough understanding of behavior in social conflict. In this section we review the growing body of research on the interpersonal effects of anger in various conflict settings, starting with negotiation.

\subsubsection{Negotiation}

Van Kleef et al. (2004a) were the first to investigate the interpersonal effects of anger in negotiations. Over the course of a computer-mediated negotiation, participants received information about their (simulated) opponent's emotional state. For example, participants would read messages from their opponent saying that "this offer makes me really angry" or "this offer makes me really happy." The results showed that participants with an angry opponent made larger concessions than did participants with a non-emotional opponent, whereas participants with a happy opponent made smaller concessions. A second study revealed that negotiators used their opponent's emotions to identify his or her limits, and subsequently used this information to make a counter-offer. Negotiators who were confronted with an angry opponent estimated the opponent's limit to be high, and to avoid costly impasse they made relatively large concessions. Conversely, negotiators with a happy opponent judged the opponent's limit to be low, felt no need to concede to avoid impasse, and accordingly made relatively small concessions. This experiment further revealed that the effects of anger and happiness are mitigated when the opponent makes large concessions and thereby undermines the focal negotiator's motivation to take the other's emotion into account. Finally, a third study indicated that the effects of anger and happiness are diminished when the focal negotiator's attention is distracted from the opponent's emotion.

Compatible findings were obtained in two experiments by Sinaceur and Tiedens (2006). In a scenario study and in a face-to-face negotiation experiment in which one of the negotiators was instructed to display either anger or no emotion, they replicated Van Kleef et al.'s (2004a) results, showing that participants conceded more to angry as opposed to non-emotional counterparts. Furthermore, and in line with Van Kleef et al's finding that negotiators use their opponent's emotions to infer the other's limit, Sinaceur and Tiedens demonstrated that the effects of anger and happiness are mediated by the focal negotiator's appraisal of the opponent's toughness, with angry opponents appearing tougher and therefore eliciting larger concessions than happy counterparts. 
These studies by Van Kleef et al. (2004a) and Sincaeur and Tiedens (2006) suggest that the interpersonal effects of anger are the result of a process of strategic decisionmaking on the part of the emotion-perceiving negotiator. In other words, negotiators seem to use the information about the other's emotion to inform their own negotiation strategy. Note, however, that negotiating is a complex and cognitively taxing venture. Negotiators need to keep in mind their own preferences and limits, and, at the same time, monitor the opponent's behavior, try to locate his or her limits, and combine all this information to design an optimal strategy. The question thus arises whether negotiators are motivated to mobilize their scarce cognitive resources to pay attention to, scrutinize, and process the strategic information that is provided by the opponent's emotions. This question was the starting point of a series of studies by Van Kleef et al. (2004b), who examined whether the effects of anger and happiness depend on the focal negotiator's information processing motivation.

In three experiments Van Kleef et al. (2004b) found strong support for a moderating role of information processing motivation. In Experiment 1, which employed the computer-mediated negotiation paradigm described earlier, the authors focused on the role of need for cognitive closure, which is a stable individual difference variable that is strongly related to the motivation to search for and process information (Kruglanski and Webster 1996; Webster and Kruglanski 1994). They found that participants with a low need for cognitive closure (i.e., a high information processing motivation) were strongly affected by the opponent's emotion, leading them to concede more to an angry opponent than to a non-emotional or happy one. In contrast, participants with a high need for closure (i.e., low information processing motivation) were unaffected by the other's emotional state. In Experiment 2, which also featured the computer simulation method, they obtained a similar pattern for a situational manipulation of information processing motivation. Participants who negotiated under low time pressure (high motivation) were strongly influenced by the other's anger, whereas those under high time pressure (low motivation) were not. Furthermore, this moderating effect of time pressure was mediated by information processing-participants who negotiated under high time pressure engaged in less thorough information processing, which rendered them impervious to the information about their counterpart's emotional state. Finally, in keeping with other research showing that power reduces the motivation to consider information about other people (e.g., De Dreu and Van Kleef 2004; Fiske and Dépret 1996; Keltner and Robinson 1997), a scenario study among lower- and middle-level managers showed that low-power negotiators (i.e., negotiators with no alternatives to a negotiated agreement; Pinkley 1995) conceded more to an angry counterpart than to a happy one, whereas high-power negotiators (i.e., negotiators with ample alternatives to a negotiated agreement) were unaffected by the other's emotion.

In a study on online negotiation, Friedman et al. (2004) obtained compatible findings. They argued that responses to another's anger expressions depend on one's position in the negotiation. Negotiators who are in a weak position, they argue, are more likely to respond in a conciliatory fashion to an opponent's anger than are negotiators occupying a strong position. In line with this reasoning, Friedman et al. found that expressions of anger elicited concessions when observers had a vulnerable position (i.e., an unfavorable reputation). However, when observers had a strong position (a favorable reputation), the other's anger expressions triggered anger in the observing party, and thereby reduced the likelihood of settlement. Interestingly, a 
similar emotional reciprocity effect was observed by Van Kleef et al. (2004a), although in their study the resulting anger did not influence the negotiated outcome.

The importance of the negotiator's (power) position in determining the interpersonal effects of anger is also underscored by Sinaceur and Tiedens' (2006) work. Their study revealed that only negotiators who had few alternatives to a negotiated agreement conceded more to an angry opponent than to a happy one; participants who had ample alternatives were unaffected by the other's emotion. Finally, replicating and extending these findings, Van Kleef et al. (2006) showed that the moderating influence of power generalizes across different samples (undergraduate students, general population, managers), research methods (laboratory experiment, field simulation, scenarios), and power bases (number of alternatives, quality of best alternative, managerial support, and legitimate power). In a series of five studies in the Netherlands and Italy, they showed that negotiators with few or poor alternatives to a negotiated agreement, little support from their management, or low legitimate power (i.e., power based on one's position in an organization) were strongly affected by their opponent's anger. In contrast, negotiators with many or highly attractive alternatives, strong support from management, or high legitimate power were immune to their counterpart's emotional state.

As one might expect, research has also documented pervasive effects of anger on interpersonal liking and related constructs. Negotiators dealing with an angry (as opposed to a happy or non-emotional) opponent have been shown to develop a more negative impression of the other (Van Kleef et al. 2004a), to be less satisfied with the negotiation afterward, and to be less willing to engage in future interaction with the same party (Kopelman et al. 2006; Van Kleef et al. 2004b). Considering these aversive consequences of anger expression in combination with the earlier mentioned emotional reciprocity (anger in one person triggers anger in the other; see Friedman et al. 2004; Van Kleef et al. 2004a), one wonders whether expressing anger can also be detrimental to a negotiator's immediate economic outcomes. Some support for this possibility is provided by Friedman et al.'s (2004) study, which demonstrated that negotiations are more likely to break down when negotiators express anger toward an opponent with a strong negotiation position. Additional evidence is provided by Kopelman et al.'s (2006) study, which showed that negotiators who expressed negative affect at the bargaining table were less likely to secure a deal than were those expressing positive affect.

These seemingly inconsistent results beg the question of when expressing anger pays and when it backfires. A number of recent studies have addressed this issue, two of which explored when expressing anger is helpful or hurtful in negotiations. These studies are discussed below. The other two studies, which addressed the pros and cons of expressing anger in ultimatum bargaining and coalition formation, will be considered in the next section.

Inspired by the classic advice to "separate the people from the problem" (Fisher and Ury 1981), Steinel et al. (in press) differentiated between emotions that are directed toward a negotiator's offer and emotions that are directed toward the negotiator as a person to reconcile the seemingly contradictory findings concerning the effects of anger on negotiator concessions. Steinel et al. (in press) reasoned that expressing anger toward the situation will lead an opponent to make large concessions, as can be predicted on the basis of a strategic decision-making perspective (see Van Kleef et al. 2004a, b). On the other hand, they contend, directing anger toward the person may produce a quite different effect. When the anger is directed toward the person instead 
of their offer, in a sense it loses some of its informative qualities. When anger is explicitly directed toward one's offer, it is relatively clear what the behavioral implications are-one should make a better offer. However, when the anger is directed toward oneself as a person, it is less clear how one should respond. Furthermore, expressing anger toward a person rather than toward their offers may elicit strong feelings of anger and antipathy in that person, which may in turn cause them to take a more compatitive stance (see Friedman et al. 2004; Kopelman et al. 2006).

To test this prediction, Steinel et al. (in press) had students engage in a computermediated negotiation against a pre-programmed opponent who expressed either anger or happiness. In half of the conditions, the emotional statements were the same as in the studies by Van Kleef et al. (2004a, b). That is, the anger (or happiness) was directed toward a person's offer, for example "this offer makes me really angry." In the other conditions, through a slight change of words, the emotion was directed toward the negotiator as a person, yielding statements such as "this person makes me really angry." The results supported the above reasoning. When emotional statements were directed toward the offer, negotiators conceded more to an angry than to a happy opponent. Mediation analyses revealed that participants strategically used the information conveyed by the other's emotion to assess the other's limits, replicating the findings of Van Kleef et al. (2004a, b). However, when the emotions were directed toward the negotiator as a person, negotiators conceded less to an angry than to a happy opponent. In this case, participants did not see useful information emotion in their opponent's emotions, and accordingly there was no mediation of perceived limits. As a result, negotiators reacted more competitively to angry rather than happy counterparts by standing firm and making small concessions. Thus, while expressing anger about a person's offer seems to pay, expressing anger at them personally may backfire.

Van Kleef and Côté (in press) also investigated when the often beneficial effects of anger may backfire. They propose a dual-process model in which the justifiability of the anger and relative power jointly determine whether a negotiator will respond to an opponent's anger by retaliating and placing competitive demands or by accommodating and conceding value. The central tenet of the model is that an opponent's expressions of anger may elicit two distinct processes. On the one hand, anger may elicit reciprocal anger and retaliatory behavior via an emotional route. On the other hand, anger may signal toughness and unwillingness to concede, which may elicit concessions in observers via a strategic route.

The model posits that the relative predictive power of these two processes depends on the power of the observing negotiator and the perceived justifiability of the anger. Power determines whether negotiators will adopt a strategic route and consider the strategic implications of a counterpart's anger or whether they have the luxury of adopting an emotional route. The perceived justifiability of the opponent's anger determines to what extent negotiators who adopt the emotional route feel inclined to retaliate, with unjustifiable anger producing stronger retaliation desires than justifiable anger. Specifically, the model predicts that low-power negotiators follow the strategic route regardless of the justifiability of the opponent's anger, leading them to concede more to both justifiably angry and unjustifiably angry opponents than to non-emotional opponents. In contrast, high-power negotiators should be more likely to follow the emotional route of the model when a counterpart expresses unjustifiable anger, leading them to concede less to unjustifiably angry opponents than to justifiably angry or non-emotional opponents.

Springer 
In a series of experiments, using different methods and operationalizations of power and justifiability, Van Kleef and Côté (in press) obtained support for the dualprocess model. First of all, results indicated that unjustifiable expressions of anger created a stronger desire to retaliate than did justifiable expressions of anger. Second, high-power negotiators processed the opponent's emotions less thoroughly than did low-power negotiators. Third, as predicted by the model, the data showed that the justifiability of the opponent's anger did not affect the behavior of low-power negotiators - they conceded uniformly to both justifiably angry and unjustifiably angry opponents (relative to non-emotional counterparts). In contrast, the justifiability of the counterpart's anger did matter when the focal negotiator had high power. Highpower participants, besides conceding less in general, were found to be especially intransigent when the opponent expressed unjustifiable anger. This study thus shows that anger may backfire if it is directed at a powerful opponent who perceives the anger as unjustified.

\subsubsection{Ultimatum bargaining}

Recently, Van Dijk et al. (2006) studied the effects of anger in an ultimatum bargaining setting by investigating how allocators respond if the recipient communicates anger. In most studies on anger and negotiation, the anger pertains to the offer (but see Steinel et al., in press, discussed above). In ultimatum bargaining, such a procedure does not apply because there is only one take-it-or-leave it offer. Therefore, to study effects of anger, the procedure was slightly adjusted. Participants first answered some general questions about how they viewed bargaining (e.g., "Strategy is important in negotiations," and "In negotiations I quickly try to reach agreement."). Subsequently, this information was (supposedly) sent to the recipient, who then reacted either in an angry or happy manner.

In their first experiment, Van Dijk et al. (2006) were able to show similar effects as reported by Van Kleef et al. (2004a, b) - participants made higher offers to angry recipients than to happy recipients. Moreover, these offers appeared to be strongly related to the recipient's limits as inferred by the participants. Participants expected that an angry recipient would want more chips than a happy recipient, and the effects of emotion on offers were fully mediated by the perceived limits. These findings thus support the view that bargainers may increase their own outcomes if they communicate anger.

Two additional experiments revealed, however, that communicating anger may also backfire. In one of these experiments, Van Dijk et al. (2006) used a similar manipulation of information as Pillutla and Murnighan (1996) used in the study we discussed before. Participants, again all in the role of allocator, were asked to bargain over 100 chips that were worth twice as much to the allocator as to the recipient. In the symmetric information conditions, participants were informed that the recipient was aware of this value difference. In the asymmetric information conditions, however, participants learned that the recipient was not aware of the difference. Before making their offer, but after the manipulation of the recipient's emotion (anger vs. happiness), participants were asked to inform the recipient about the value of the chips. They could either do this truthfully, or they could misinform the recipient by stating that the chips were of equal value. Interestingly, the data showed that participants were especially likely to deceive the angry recipient (as opposed to the happy one). Moreover, after having tricked the angry recipient into believing that chips were of 
equal value, participants subsequently tended to offer the angry recipient only half of the chips. Note that this may seem fair to the deceived recipient, but actually should be regarded as a very low and unfair offer because it means that the allocator runs off with twice as many chips as the recipient.

Additional data indicated that, before the exchange of information, participants expected the limits of an angry participant to higher than the limits of a happy recipient. However, after having deceived the angry recipient, the limits that they ascribed to the angry recipient dropped dramatically, suggesting that the participants reasoned that after having led the recipient to believe that chips were of equal value, they could get away with low offers (i.e., by offering only half of the chips). What this experiment shows is that communicating anger may backfire if your opponent has the possibility to deceive you. By communicating anger you may signal high limits, but deception offers your opponent the opportunity to make low offers and trick you into believing that these are actually quite high. Because it has generally been acknowledged that negotiations and bargaining situations are ripe with possibilities for deception (e.g., Bok 1978; Boles et al. 2000; O'Connor and Carnevale 1997; Steinel and De Dreu 2004), this constitutes an important moderator of the effects of communicated anger.

In a subsequent experiment, Van Dijk et al. (2006) continued their search for possible moderators of the effects of communicated anger by investigating the consequences of rejection in an ultimatum game setting. It may be noted that in the typical ultimatum bargaining setting, the consequences of the recipient rejecting the allocator's offer are high-If the recipient rejects the offer, both players end up with zero outcomes. The consequences need not always be that extreme, however. To study what happens if the consequences are less severe, Van Dijk et al. investigated behavior in a modified version of the ultimatum game that has also been referred to as the delta game (Suleiman 1996; Van Dijk and Tenbrunsel 2005). In this version, the offer is multiplied by a factor delta $(0 \leq$ delta $\leq 1)$. Thus, for delta $=0$, the delta game is identical to the standard ultimatum game (i.e., if the recipient rejects, the recipient and the allocator both end up with nothing). With higher values of delta, the consequences of rejection become less severe. In Van Dijk et al's experiment, delta was set at 0.9 , meaning that if the recipient would reject the offer, it would only be reduced with $10 \%$. With this setup, it was again demonstrated that communicating anger may backfire. Using a similar way of manipulating the recipient's emotion as in the other two experiments, Van Dijk et al. showed that when the consequences of rejection were low (i.e., delta $=0.9$ ), participants offered fewer chips to an angry recipient that to a happy one. Moreover, they made these offers while being convinced that the limits of an angry recipient were higher than the limits of a happy recipient. Apparently, signaling high limits to an allocator by communicating anger is not a wise thing to do for a recipient when the consequences of rejection are low. After all, when the consequences of rejection are low, people may simply not care too much for your limits, even if they are high.

Taken together these findings on ultimatum bargaining suggest that it may not always pay to communicate anger. A general advice for bargainers would therefore be to first assess the bargaining situation in terms of the consequences of rejecting offers and the possibilities for deception before deciding on whether or not to show anger. 


\subsubsection{Coalition formation}

Above we showed how anger affects social conflict when two parties negotiate. A growing body of research indicates that in many cases it pays to get angry. That is, either one increases ones payoffs by expressing anger or expressing anger has no effect (Sinaceur and Tiedens 2006; Van Kleef et al. 2004a, b, 2006). Recent studies of anger in negotiation and ultimatum bargaining paint a somewhat more complicated picture, whereby anger may have beneficial effects at some times and detrimental effects at other times (Steinel et al., in press; Van Dijk et al. 2006; Van Kleef and Côté, in press). The story may be even more complex in multi-party coalition negotiations. What happens in situations in which more than two parties negotiate? Is it beneficial to express anger in such situations?

To get a grasp on multi-party bargaining situations it is necessary to consider that in this case people are not only concerned with whether they reach an agreement but also with the question with whom they reach an agreement. This feature increases the complexity of the situation dramatically (Bolton et al. 2003; Kramer 1991). Indeed, an important difference between two- and multi-party situations is that the latter allow for the formation of coalitions (Bazerman et al. 2000; Van Beest et al. 2005). Whereas in two-party negotiation researchers focus on whether or not both parties reach an agreement, multi-party negotiation researchers also focus on who is included and excluded in an agreement. Consequently, the question to answer is not merely how negotiators allocate payoffs but also who gets them and who does not.

A specific research tradition that aims to answer these questions concerns the field of coalition formation (Kahan and Rapoport 1984; Murnighan 1978; Wilke 1985). A leading assumption in coalition formation research is that people aim to maximize their own payoffs and thus that people prefer to form a coalition with few people to a coalition with many people (Van Beest et al. 2004a). In fact, a core assumption of most coalition theories is that people should never form a coalition that includes all parties. An interesting phenomenon that is based on this motivation to maximize one's own payoff is the so-called "strength is weakness" principle (Vinacke and Arkoff 1957; Chertkoff 1971; Murnighan 1991). This principle states that parties who have more resources than others may end up having nothing because it is more beneficial for weak parties to form a coalition with other weak parties than it is to form a coalition with a strong party. To illustrate, consider a situation in which three parties that differ in strength negotiate about 100 euros. Party A controls 4 votes, Party B controls 3 votes, and party $\mathrm{C}$ controls 2 votes. Given that each party wants to maximize their own payoffs it is clear that Party $\mathrm{A}$ is better off forming a coalition with party $\mathrm{C}$ than with party $\mathrm{B}$. Note, however, that $\mathrm{B}$ and $\mathrm{C}$ are better off forming a $\mathrm{BC}$-coalition than an AB- or AC-coalition. Hence, the strongest party is excluded because both party $\mathrm{B}$ and party $\mathrm{C}$ obtain most in a $\mathrm{BC}$-coalition.

Using this logic, Van Beest et al. (2006) argued that a perverse side-effect of communicating toughness in a multi-party setting is that parties believe that it is more beneficial to form a coalition with weak parties than with tough parties. More specifically, they argued that in multi-party settings anger may communicate toughness but consequently people may avoid forming a coalition with those who raise their voice.

To test this proposition the authors conducted two experiments. In the first experiment they focused on the opening stage of a three-player coalition game. Participants were selected to make an opening offer to one of the other players, and based on condition the included player (i.e., included in the proposal), the excluded player 
(i.e., excluded in the proposal), or none of the players was allowed to comment on the proposal. Results showed that if none commented on the opening proposal, participants did not change their proposal. However, the more interesting finding was that participants changed their proposal more often when the included player got angry than when the excluded player got angry. In contrast to a two-party situation in which people may feel a strong need to reach an agreement with an angry player, participants now chose to reach an agreement with a non-angry player by excluding the angry one. Thus, in contrast to two-party situations in which anger often increases ones payoffs, these findings show that in multi-party coalition formation angry players get less than non-angry players.

In a second experiment Van Beest et al. (2006) focused on the closing stage of a coalition formation procedure. Now anger was voiced after a first proposal to form a coalition had failed. Again, the results were clear. In both the included and control condition, participants tried to form a coalition with another person, whereas in the excluded condition participants retried forming a coalition with their original partner. In this experiment anger overpowered the urge to join forces with another person. Yet, similar to the first experiment, angry players were again not included in the final coalition. Together, these experiments indicate that expressing anger in multi-party negotiation may be even more risky than expressing anger in dyadic negotiation.

\subsection{Cross-situational comparisons and propositions}

Above we reviewed all the studies we are aware of that explicitly addressed the role of discrete anger (as opposed to general negative affect) in social conflict. This overview provides a number of interesting insights, to which we now turn.

It appears that the intrapersonal effects of anger are quite straightforward and clear-cut. Regardless of whether we focus on negotiation, ultimatum bargaining, prisoner's dilemma, or resource dilemma, anger seems to elicit competitive behavior. The robustness of this effect is striking, especially in light of the much more complicated role of anger at the interpersonal level of analysis. In contrast to the interpersonal effects of anger, the intrapersonal effects seem to hold regardless of differences in dependence structures or other aspects of the social situation. It would appear that there is a hardwired relation between the experience of anger and competitive behavior, which is not moderated by characteristics of the situation.

In contrast, the interpersonal effects of anger appear to be heavily dependent on variations in the social context. Our review has identified three different types of interpersonal effects of anger on behavior: beneficial effects, null effects, and detrimental effects. Beneficial effects of anger were observed in two-person negotiation and ultimatum bargaining situations in which the target of the anger was in some way dependent on the expresser and was motivated and able to consider the implications of the other's anger. For example, beneficial effects of anger were observed when the target of the anger had few or poor alternatives to a negotiated agreement (Sinaceur and Tiedens 2006; Van Kleef et al. 2004b), when the target had relatively low power (Van Kleef et al. 2006), and when the expresser made small concessions, thereby increasing the dependence of the target on the expresser relative to a situation in which the expresser would make large concessions (Van Kleef et al. 2004a). Relatedly, beneficial effects of anger were observed when the target of the anger was motivated to pay attention to and process the other's anger. For instance, we have seen that anger may have advantageous effects for the expresser when the target has a 
low need for cognitive closure and/or is under low time pressure, both conditions that are conducive to thoughtful and elaborate information processing (Van Kleef et al. 2004b).

Our review also identified conditions under which anger is likely to have no effects on a target. When the target has many or highly attractive alternatives to a negotiated agreement (Sinaceur and Tiedens 2006; Van Kleef et al. 2004b) or has high power stemming from other sources, such as support from management or a prominent position in the organization (Van Kleef et al. 2006), then the expresser's anger is unlikely to have an effect on the target. Relatedly, we have seen that reduced information processing motivation also mitigates the interpersonal effects of anger. For example, negotiators with a high need for cognitive closure and/or under high time pressure have been found to be impervious to their counterpart's anger expressions (Van Kleef et al. 2004b).

Finally, our review reveals that there are conditions under which it may actually be detrimental to express anger in conflict. A recent study by Steinel et al. (in press) showed that anger may backfire when it is directed at the person instead of at the situation (i.e., the person's offer). In this case, negotiators may be worse off if they express their anger. In similar vein, Van Kleef and Côté (in press) demonstrated that anger may be detrimental if the target of the anger has high power and perceives the anger as unjustifiable. Furthermore, Van Dijk et al. (2006) found that anger was counterproductive when the consequences of rejecting an angry counterpart's offer were low or when targets had the opportunity to deceive the counterpart. Finally, Van Beest et al. (2006) demonstrated that it may generally be unwise to display anger in multi-party negotiation. Parties who were part of an initial coalition were more likely to be excluded from the final coalition if they expressed anger rather than no emotion, and parties who were not part of a coalition proposal reduced their chances of ending up being in the final coalition if they expressed anger rather than no emotion.

Based on this summary, we propose that three, partly interrelated, classes of moderators jointly determine whether expressing anger in conflict will prove helpful or harmful:

I. Interdependence structure. It appears that expressing anger is more likely to produce favorable outcomes to the extent that the target of the anger is more dependent on the expresser. The current review shows that, among other things, interdependence may be influenced by the relative power of the parties (Van Kleef et al. 2006), their alternatives (Sinaceur and Tiedens 2006; Van Beest et al. 2006; Van Kleef and Côté, in press), and the existence of opportunities to deceive (Van Dijk et al. 2006).

II. Information processing. Our overview revealed that information processing plays an important role in determining whether anger has an effect or not. Specifically, the positive effects of anger appear to increase to the extent that individuals are more likely to process the information inherent in the emotion (Van Kleef et al. 2004b) and to the extent that the anger itself has greater informational value (Steinel et al., in press). Negotiators with a high motivation to engage in thorough and deliberate information processing were found to be strongly influenced by their opponent's anger expressions, while those with a low information processing motivation were unaffected by the other's anger.

III. Justifiability. A third class of variables that seems to play a role relates to the justifiability of the anger expression. Expressions of anger are more likely to 
prove successful in eliciting desired behavior to the extent that the anger is perceived as justifiable, whereas anger is more likely to prove hurtful to the extent that it is deemed unjustifiable (Van Kleef and Côté, in press). More specifically, negotiators who perceive their counterpart's anger as unjustifiable tend to respond relatively competitively to the other's anger, especially if they have relatively high power. In contrast, negotiators who deem the other's anger justifiable tend to respond more cooperatively.

\subsection{Avenues for future research}

Our overview of research on anger in conflict also reveals a number of caveats in our current knowledge. First, despite the fact that studies of the intrapersonal effects of anger in social conflict have yielded highly consistent results across different research methods, operationalizations, and conflict settings, an important question remainswhy do angry disputants behave more competitively than non-angry disputants? The underlying processes responsible for the intrapersonal effects of anger have not yet been uncovered, and this poses an interesting and important challenge for future research. One possible explanation for the intrapersonal effects of anger is suggested by research on emotions and risk taking. It may be that anger "clouds" perceptions of danger and disposes individuals to take more risks (Lerner and Keltner 2001), which could become manifest in tough demands. Another explanation can be derived from the mood management literature, which has documented that individuals in a negative emotional state are often motivated to take action to improve their mood (Mayer et al. 1991). Following this reasoning, an angry negotiator may be motivated to improve his or her emotional state by trying to get the most out of the negotiation. Future research could investigate the mechanisms underlying the intrapersonal effects of anger.

Research along these lines might also reveal whether people are sensitive to the possible consequences of showing anger. We have probably all encountered situations in which we felt anger, but decided to swallow our anger. On occasion, we may also have exaggerated our anger when complaining about bad service, because we felt it would help us to achieve a better deal. As our review has shown, communicating anger may often pay, but on occasion also backfire, suggesting that it may sometimes be better to not show one's anger (if anger would backfire), and sometimes even to fake anger (if it pays). Are bargainers prepared to strategically show anger in order to get a better deal? And if so, will they strategically refrain from showing anger if they realize that their opponent has little to fear from them? Getting answers to questions like these seems essential for a better understanding of the interpersonal effects of anger.

Another caveat concerns the role of anger in more intimate or communal relationships as opposed to the exchange relationships that were the focus of the present article, especially when it comes to interpersonal effects. In fact, we are unaware of any attempt to systematically investigate the interpersonal effects of anger in close relationships. Can the interpersonal effects of anger in close relationships be understood in terms of the three classes of moderators that we proposed above, interdependence, information processing, and justifiability? Or do different mechanisms apply in more communal relations? We believe that exploring the interpersonal role of anger in close relationships would constitute a fruitful area of future research. 
Another avenue for future study concerns the long-term consequences of anger. How does anger influence the relationship between parties in conflict over time? Do the beneficial effects of anger persist over time, or do they diminish or even backfire in the long run? Research has shown that negotiators with an angry opponent become angry themselves, are less satisfied with the negotiation, and are less willing to engage in future interaction with the same opponent (Friedman et al. 2004; Van Kleef et al. $2004 a, b)$ than are negotiators with non-angry counterparts. This notion points to an interesting dilemma facing negotiators who anticipate future interaction. On the one hand, negotiators may be motivated to strategically suppress anger in order to make a good impression and to induce or maintain a positive interpersonal relationship. On the other hand, they may choose to use anger to get their opponents to go along with their preferences. Future research could investigate which of these strategies is more beneficial in the long run.

Still another avenue for future research concerns the role of conflict issues in negotiations. Negotiations may involve interests, factual issues and normative issues (Harinck 2004; Harinck and De Dreu 2004; Harinck et al. 2000). The conflict issue at hand in the negotiation influences the extent to which parties reach win-win agreements, and how they communicate with each other. More specifically, negotiators are less likely to yield to the other party or to engage in logrolling when normative issues rather than interests are at stake. Given that moral values are central to personal identity (Rokeach 1973), people are motivated to affirm their sense of self by endorsing self-expressive moral positions or "moral mandates" (Skitka 2002). Individuals' concomitant attachment to their norms and values renders trade-offs on moral dimensions inappropriate (Tetlock et al. 2000; Thompson and Gonzalez 1996; Wade-Benzoni et al. 2002). Extending this line of reasoning, it could be predicted that interpersonal anger is less effective or even harmful when the negotiation centers around normative or values issues rather than interests, due to parties' unwillingness to give in on those issues. (See Druckman et al. 1977, for evidence on intransigence for values issues.) Future research could test whether conflict issues indeed moderate the interpersonal effects of anger.

\subsection{Conclusion}

After having been neglected for decades, scholarly interest for the role of anger in social conflict has rapidly grown in this century. The aim of this paper was to provide an overview of the expanding literature on anger in conflict. Our review of the intrapersonal effects of anger suggests a straightforward and robust relationship between anger and behavior-experiencing anger leads parties to take a competitive stance in the conflict. This effect seems to generalize across different conflict settings. The interpersonal effects of anger appear to be more complicated, with expressions of anger sometimes eliciting cooperation, sometimes eliciting competition, and sometimes having no effect whatsoever. Based on the research that is available to this point, we account crucial moderating roles to the level of interdependence of the parties, their information processing tendencies, and the justifiability of the anger expression in determining the interpersonal effect of anger on conflict behavior.

About 15 years after the first systematic investigation of the role of anger in conflict, we have come to know a lot about its effects and the mechanisms through which it exerts these effects. However, many big questions remain, and future research is 
needed to further increase understanding of the role of anger in conflict. It is our hope that this article will prove to be a source of inspiration for future research endeavors.

\section{References}

Allred KG (1999) Anger and retaliation: toward an understanding of impassioned conflict in organizations. Res Negotiat Organ 7: 27-58

Allred KG, Mallozzi JS, Matsui F, Raia CP (1997) The influence of anger and compassion on negotiation performance. Organ Behav Human Decis Process 70: 175-187

Averill JR (1982) Anger and aggression. Springer, New York

Baron RA (1990) Environmentally induced positive affect: It's impact on self-efficacy, task performance, negotiation, and conflict. J Appl Soc Psychol 20: 368-384

Baron RA, Fortin SP, Frei RL, Hauver LA, Shack ML (1990) Reducing organizational conflict: the role of socially-induced positive affect. Int J Conflict Manage 1: 133-152

Barry B, Fulmer IS, Van Kleef GA (2004) I laughed, I cried, I settled: the role of emotion in negotiation. In: Gelfand MJ, Brett JM (eds) The handbook of negotiation and culture. Stanford University Press, pp 71-94

Bazerman MH, Curhan JR, Moore DA, Valley KL (2000) Negotiation. Annu Rev Psychol 51: 279_ 314

Bok S (1978) Lying: Moral choice in public and private life. Pantheon Books, New York

Boles TL, Croson RTA, Munighan JK (2000) Deception and retribution in repeated ultimatum bargaining. Organ Behav Human Decis Process 83: 235-259

Bolton GE, Chatterjee K, McGinn KL (2003) How communication links influence coalition bargaining: a laboratory investigation. Manage Sci 49: 583-598

Butt AN, Choi JN, Jaeger AM (2005) The effects of self-emotion, counterpart emotion, and counterpart behavior on negotiator behavior: a comparison of individual-level and dyad-level dynamics. J Organ Behav 26: 681-704

Camerer C, Thaler RH (1995) Anomalies: ultimatums, dictators, and manners. J Econ Perspect 9: 209-219

Carnevale PJ, Isen AM (1986) The influence of positive affect and visual access on the discovery of integrative solutions in bilateral negotiation. Organ Behav Human Decis Proces 37: 1-13

Chertkoff JM (1971) Coalition formation as a function of differences in resources. J Conflict Resolut 15: $371-383$

Daly JP (1991) The effects of anger on negotiations over mergers and acquisitions. Negotiat J 7: 31-39

Darwin C (1872) The expression of the emotions in man and animals 3rd edn. HarperCollins, London

Dawes RM (1980) Social dilemmas. Ann Rev Psychol 31: 169-193

De Dreu CKW, Van Kleef GA (2004) The influence of power on the information search, impression formation, and demands in negotiation. J Exp Soc Psychol 40: 303-319

Druckman D, Rozelle M, Zechmeister K (1977) Conflict of interest and value dissensus: two perspectives. In: Druckman D (ed) Negotiations: social-psychological perspectives.. Sage, Beverly Hills CA

Ekman P (1993) Facial expression and emotion. Am Psychol 48: 384-392

Fisher R, Ury W (1981) Getting to yes. Penguin Books, New York

Fiske ST, Dépret E (1996) Control, interdependence, and power: Understanding social cognition in its social context. In: Stroebe W, Hewstone M (eds) European review of social psychology vol 7. Wiley, Chichester England, pp 31-61

Forgas JP (1998) On feeling good and getting your way: mood effects on negotiator cognition and behavior. J Pers Soc Psychol 74: 565-577

Fridlund AJ (1992) The behavioral ecology and sociality of human faces. In: Clark MS (ed) Review of personality and social psychology, vol 13 . Sage, Thousand Oakes, CA, pp 90-121

Friedman R, Anderson C, Brett J, Olekalns M, Goates N, Lisco CC (2004) The positive and negative effects of anger on dispute resolution: evidence from electronically mediated disputes. J Appl Psychol 89: 369-376

Frijda NH (1986) The emotions. Cambridge University Press, Cambridge 
Frijda NH, Mesquita B (1994) The social roles and functions of emotions. In: Kitayama S, Markus HS (eds) Emotion and culture: empirical studies of mutual influence. American Psychological Association, Washington, DC, pp 51-87

Güth W, Tietz R (1990) Ultimatum bargaining behavior: a survey and comparison of experimental results. J Econ Psychol 11: 417-449

Güth W, Schmittberger R, Schwarze B (1982) An experimental analysis of ultimatum bargaining. J Econ Behav Org 3: 367-388

Handgraaf MJJ, Van Dijk E, De Cremer D (2003) Social utility in ultimatum bargaining. Soc Justice Res 16: 263-283

Harinck F (2004) Persuasive arguments and beating around the bush in negotiations. Group Process Intergroup Relat 7: 5-17

Harinck F, De Dreu CKW (2004) Negotiating interests or values and reaching integrative agreements: the importance of time pressure and temporary impasses. Eur J Soc Psycho 34: 595-611

Harinck F, De Dreu CKW, VanVianen AE M (2000) The impact of conflict issue on fixed-pie perceptions, problem solving, and integrative outcomes in negotiation. Organ Behav Human Decis Proces 81: 329-358

Kahan JP, Rapoport A (1984) Theories of coalition formation. Erlbaum, Hillsdale NJ

Kassinove H, Roth D, Owens SG, Fuller JR (2002) Effects of trait anger and anger expression style on competitive attack responses in a wartime prisoner's dilemma game. Aggress Behav 28: $117-125$

Keltner D, Haidt J (1999) Social functions of emotions at four levels of analysis. Cognit Emotion 13: 505-521

Keltner D, Robinson RJ (1997) Defending the status quo: power and bias in social conflict. Pers Soc Psychol Bull 23: 1066-1077

Klinnert M, Campos J, Sorce J, Emde R, Svejda M (1983) Emotions as behavior regulators: social referencing in infants. In: Plutchik R, Kellerman $\mathrm{H}$ (eds) Emotion theory, research, and experience, vol 2. Academic Press, New York, pp 57-68

Knapp A, Clark M (1991) Some detrimental effects of negative mood on individuals' ability to solve resource dilemmas. Pers Soc Psychol Bull 17: 678-688

Knutson B (1996) Facial expressions of emotion influence interpersonal trait inferences. J Nonverbal Behav 20: 165-182

Kopelman S, Rosette AS, Thompson L (2006) The three faces of eve: an examination of the strategic display of positive, negative, and neutral emotions in negotiations. Org Behav Human Decis Process 99: 81-101

Kramer RM (1991) Intergroup Relations and Organizational Dilemmas - the Role of categorization Processes. Res Organ Behav 13: 191-228

Kruglanski AW, Webster DM (1996) Motivated closing of the mind: "Seizing" and "freezing". Psychol Rev 103: 263-283

Lerner JS, Keltner D (2001) Fear, anger, and risk. J Pers Soc Psychol 81: 146-159

Mayer JD, Salovey P, Gomberg-Kaufman S, Blainey K (1991) A broader conception of mood experience. J Pers Soc Psychol 60: 100-111

Messick DM, Brewer MB (1983) Solving social dilemmas: A review. In: Wheeler L, Shaver P (eds) Review of personality and social psychology, vol 4. Sage, Beverley Hills, CA, pp 11-44

Morris MW, Keltner D (2000) How emotions work: an analysis of the social functions of emotional expression in negotiations. Res Organ Behav 22: 1-50

Murnighan JK (1978) Models of coalition behavior: game theoretic, social psychological, and political perspectives. Psychol Bull 85: 1130-1153

Murnighan JK (1991) The dynamics of bargaining games. Prentice Hall, Englewood Cliffs, NJ

Oatley K, Jenkins JM (1992) Human emotions: function and dysfunction. Annu Rev of Psychol 43: 55-85

O'Connor KM, Carnevale PJ (1997) A nasty but effective negotiation strategy: misrepresentation of a common-value issue. Pers Soc Psychol Bull 23: 504-515

Parkinson B (1996) Emotions are social. Brit J Psychol 87: 663-683

Pillutla MM, Murnighan JK (1996) Unfairness, anger, and spite: emotional rejections of ultimatum offers. Organ Behav Human Decis Process 68: 208-224

Pinkley RL (1995) Impact of knowledge regarding alternatives to settlement in dyadic negotiations: whose knowledge counts?. J Appl Psychol 80: 403-417

Pruitt DG, Carnevale PJ (1993) Negotiation in social conflict. Open University Press, Buckingham, England

Rokeach M (1973) The nature of human values. Free Press, New York 
Sinaceur M, Tiedens LZ (2006) Get mad and get more than even: when and why anger expression is effective in negotiations. J Exp Soc Psychol 42: 314-322

Skitka LJ (2002) Do the means always justify the ends, or do the ends sometimes justify the means? A value protection model of justice reasoning. Pers Soc Psychol Bull 28: 588-697

Steinel W, De Dreu CKW (2004) Social motives and strategic misrepresentation in social decision making. J Pers Soc Psychol 86: 419-434

Steinel W, Van Kleef GA, Harinck F (in press) Are you talking to me?! Separating the people from the problem when expressing emotions in negotiation. J Exp Soc Psychol

Suleiman R (1996) Expectations and fairness in a modified ultimatum game. J Econ Psychol 17: 531-554

Thaler RH (1988) Anomalies: the ultimatum game. J Econ Perspect 2: 195-206

Tetlock PE, Kristel OV, Elson SB, Green MC, Lerner JS (2000) The psychology of the unthinkable: taboo trade-offs, forbidden base-rates, and heretical counterfactuals. J Pers Soc Psychol 78: 853-870

Thompson L, Gonzalez R (1996) Environmental disputes; competition for scarce resource and clashing of values. In: Bazerman MH, Messick DM, Tenbrunsel AE, Wade-Benzoni KA (eds) Environment, ethics, and behavior.. New Lexington Press, San Francisco, pp 75-104

Van Beest I, Van Dijk E, De Dreu CKW, Wilke HAM (2005) Do-no-harm in coalition formation: why losses inhibit exclusion and promote fairness cognitions. J Exp Soc Psychol 41(6): 609-617

Van Beest I, Van Dijk E, Wilke HAM (2004a) The interplay of self-interest and equity in coalition formation. Eur J Soc Psychol 34: 547-565

Van Beest I, Van Dijk E, Wilke HAM (2004b) Resources and alternatives in coalition formation: the effects on payoff, self-serving behavior, and bargaining length. European J Soc Psychol 34: $713-728$

Van Beest I, Van Kleef GA, Van Dijk E (2006) When raisings one's voice lowers one's payoff: the effects of anger in multi-party negotiation. Paper presented at the 18th annual conference of the International Association for Conflict Management, Seville, Spain

Van Dijk E, Tenbrunsel A (2005) The battle between self-interest and fairness in bargaining: ultimatum, dictator, and delta games. In: Gilliland SW, Steiner DD, Skarlicki DP, Vanden Bos K (eds) What motivates fairness in organizations? [In Gilliland SW, Steiner DD, Skarlicki DP (Series Eds), Res social issues in management].. Greenwich CT, Information Age Publishing, pp, pp 31-48

Van Dijk E, Van Kleef GA, Steinel W, Van Beest I (2006) Emotions in bargaining: when communicating anger pays and when it backfires. Manuscript submitted for publication

Van Kleef GA, Côté S (in press) Expressing anger in conflict: when it helps and when it hurts. J Appl Psychol

Van Kleef GA, De Dreu CKW, Manstead ASR (2004a) The interpersonal effects of anger and happiness in negotiations. J Pers Soc Psychol 86: 57-76

Van Kleef GA, De Dreu CKW, Manstead ASR (2004b) The interpersonal effects of emotions in negotiations: a motivated information processing approach. J Pers Soc Psychol 87: 510-528

Van Kleef GA, De Dreu CKW, Pietroni D, Manstead ASR (2006) Power and emotion in negotiations: Power moderates the interpersonal effects of anger and happiness on concession making. Eur J Soc Psychol 36: 557-581

Vinacke WE, Arkoff A (1957) An experimental study of coalitions in the triad. Ame Soc Rev 22: 406-414

Wade-Benzoni KA, Hoffman AJ, Thompson LL, Moore DA, Gillespie JJ, Bazerman MH (2002) Barriers to resolution in ideologically based negotiations: the role of values and institutions. Acad Manage Rev 27: 41-57

Webster DM, Kruglanski AW (1994) Individual differences in need for cognitive closure. J Person Soc Psychol 67: 1049-1062

Wilke HAM (1985) Coalition formation. Elsevier, New York 